\title{
UJI PERAN ABUSIVE SUPERVISION SEBAGAI MEDIATOR : HUBUNGAN MACHIAVELLIANISM DENGAN PERILAKU KERJA KONTRAPRODUKTIF
}

\author{
Yuliana $^{1}$ dan P. Tommy, Y. S. Suyasa ${ }^{2}$ \\ ${ }^{1}$ Fakultas Psikologi, Universitas Tarumanagara Jakarta \\ Email:yulianawawa.agem@gmail.com \\ ${ }^{2}$ Fakultas Psikologi, Universitas Tarumanagara, Jakarta \\ Email: tommys@fpsi.untar.ac.id
}

\begin{abstract}
The purpose of this study is to examine the role of abusive supervision as the mediator between machiavellianism and counterproductive work behavior (PKK). PKK is a behavior carried out intentionally by individuals that conflicts with the goals, rules, and norms of the organization which negatively affects the organization and its members. Machiavellianism is a personality trait that is characterized by the tendency of cynical beliefs towards others and manipulative actions for personal gain (such as money, power, and status). Abusive supervision is the subjective perception of the subordinates regarding the extent to which the behavior of the supervisor is deemed unpleasant both verbally and nonverbally, but does not involve physical contact. This study involves 337 participants who worked as employees at a spring bed manufacturing company. Data analysis was performed using path analysis method with Smart-PLS software version 3.2.7. The result of the study shows that abusive supervision acts as a full mediator between machiavellianism and PKK.

Keywords: Machiavellianism, counterproductive work behavior, abusive supervision .
\end{abstract}

\begin{abstract}
ABSTRAK
Tujuan penelitian ini adalah untuk menguji peran abusive supervision sebagai mediator hubungan machiavellianism dengan perilaku kerja kontraproduktif (PKK). PKK merupakan perilaku yang dilakukan oleh individu secara sengaja yang bertentangan dengan tujuan, aturan, dan norma organisasi serta dapat memberikan efek negatif bagi organisasi dan anggota di dalamnya. Machiavellianism merupakan sifat kepribadian yang dikarekteristikan dengan kecenderungan keyakinan sinis terhadap orang lain dan tindakan manipulatif untuk mencapai keuntungan pribadi (seperti uang, kekuasaan, dan status). Abusive supervision adalah persepsi subyektif dari bawahan mengenai sejauh mana perilaku atasan dinilai tidak menyenangkan baik perilaku verbal maupun non verbal, namun tidak melibatkan kontak fisik. Penelitian ini melibatkan 337 partisipan yang bekerja sebagai karyawan di perusahaan manufaktur kasur pegas. Analisis data dilakukan dengan metode path analysis dengan software Smart-PLS versi 3.2.7. Hasil penelitian menunjukkan abusive supervision berperan sebagai mediator secara penuh hubungan machiavellianism dengan PKK.
\end{abstract}

Kata kunci: Machiavellianism, perilaku kerja kontraproduktif, abusive supervision.

\section{PENDAHULUAN \\ Latar belakang}

Menurut Sackett dan De Vore (dalam Anderson, 2005) perilaku kerja kontraproduktif (PKK) mencakup segala bentuk perilaku yang dilakukan dengan sengaja oleh anggota organisasi yang bertentangan dengan tujuan atau kepentingan organisasi serta membahayakan organisasi dan anggotanya (Robinson \& Bennett, 1995). PKK dapat menghambat organisasi dalam mencapai tujuan tersebut (Anderson, 2005). Definisi PKK ini mencakup perilaku yang sangat umum seperti pencurian, sabotase, penggunaan obat-obatan, ketidakhadiran, dan kekerasan/kejahatan interpersonal (Spector, Fox, Penney, Bruursema, Goh, \& Kessler, 2006).

Penelitian sebelumnya menekankan bahwa pentingnya mengidentifikasikan karakteristik kepribadian yang mungkin berhubungan dengan PKK (Baloch, Meng, Cepeda-Carrion, Danish, \& Bari, 2017). Peneliti menemukan banyak penelitian yang menggunakan The Big Five Personality dalam hubungannya dengan PKK (Nurul, Kozako, Safim, \& Rahim, 2013; Hafidz, 
2012; Michael, Ilies, \& Johnson, 2006; Raman, Sambasivan, \& Kumar, 2016; Bolton, Becker, \& Barber, 2010; Scott \& Judge, 2013; Piskin, Kart, Savci, \& Guldu, 2014; Thakur, 2017; Jensen \& Patel, 2011). Namun, penelitian yang melihat PKK dari dark triad personality masih jarang ditemukan (Baloch et al., 2017; Cohen, 2016).

Di antara dark triad personality, hubungan machiavellianism dengan PKK masih kurang konsisten. Beberapa studi telah mengkaji hubungan antara machiavellianism dengan PKK dan ditemukan bahwa ada adanya hubungan positif yang signifikan antara machiavellianism dengan PKK (Amir \& Malik, 2016; Baloch et al., 2017; Kessler, 2010; O’Boyle \& Forsyth, 2012). Hasil penelitiannya menunjukkan bahwa individu dengan machiavellianism yang tinggi akan semakin terlibat dalam PKK untuk mencapai tujuan dan keinginannya (Amir \& Malik, 2016). Karyawan dengan machiavellianism yang tinggi cenderung terlibat dalam perilaku kerja yang tidak etis dan kontraproduktif (Kish-Gephart et al., 2010; O’Boyle et al., 2012). Namun, di sisi lain penelitian dari Stanescu dan Mohorea (2016) menunjukkan bahwa machiavellianism tidak memprediksi secara signifikan PKK pada pekerja.

Machiavellianism merupakan sifat kepribadian dikarakteristikkan dengan keyakinan sinis terhadap orang lain, tidak berperasaan, dan berusaha mencapai tujuan tertentu (seperti uang, kekuasaan, dan status), serta taktik penipuan atau manipulasi (Christie \& Geis dalam Wisse \& Sleebos, 2016). Penelitian terbaru menunjukkan bahwa karyawan dengan machiavellianism yang tinggi dapat menganggu fungsi efektif organisasi (O'Boyle, Forsyth, Banks, \& Mc Daniel, 2012). Individu dengan machiavellianism yang tinggi memiliki peluang yang lebih besar untuk terlibat dalam perilaku yang menuntun mereka mencapai tujuan pribadinya dan percaya bahwa "segala cara adalah benar" (Amir \& Malik, 2016). Jika machiavellianism dan PKK memiliki hubungan yang tidak konsisten, maka penting untuk ditelusuri variabel yang dapat menjelaskan ketidakkonsitenan ini. Peneliti menduga inkonsistensi hubungan machiavellianism dengan PKK memerlukan variabel mediator agar lebih konsisten.

Abusive supervision merupakan salah satu faktor yang mempengaruhi PKK dan dapat diusulkan sebagai variabel mediator. Tepper (2000) menjelaskan bahwa abusive supervision adalah persepsi bawahan terkait sejauh mana atasan melakukan perilaku yang dianggap kurang baik oleh mereka, baik secara verbal maupun non verbal yang dilakukan secara terus menerus, tetapi tidak melibatkan kontak fisik. Perilaku seperti itu biasanya termasuk mengejek dan mempermalukan bawahan di depan umum, menolak untuk berbicara dengan bawahan, dan atau meremehkan bawahan (Uzondu, Nwonyi, \& Ugwungbor, 2017).

Beberapa penelitian menemukan bahwa abusive supervision memiliki hubungan yang positif dengan perilaku kontraproduktif karyawan (An \& Wang, 2016; Mackey, Frieder, Bress, \& Martinko, 2015; Sulea et al., 2013; Uzandu et al., 2017). Korban dari atasan yang abusif cenderung kurang berkomitmen dengan organisasi dan lebih besar mengarah pada PKK (Uzandu et al., 2017). Penelitian lain juga menemukan bahwa terdapat hubungan yang signifikan antara machiavellianism dengan abusive supervision (Greenbaum, Hill, Mauritz, \& Quade, 2014; Kiazad et al., 2010; Wise \& Skebos, 2016).

Berdasarkan pemaparan di atas, peneliti tertarik untuk meneliti peran abusive supervision sebagai mediator dalam hubungan machiavellianism dengan PKK. Penelitian ini diharapkan dapat memberikan sumbangan dalam bidang akademis untuk lebih menggali peranan dari variabel abusive supervision, serta memastikan mengenai hubungan antara machiavellianism 
dengan PKK. Selain itu juga perusahaan dapat menyadari bagaimana mengelola sumber daya manusia khususnya pada karyawan perusahaan.

\section{Rumusan masalah}

Apakah abusive supervision berperan sebagai mediator pada hubungan machiavellianism dengan perilaku kerja kontraproduktif di PT X ?

\section{METODE PENELITIAN}

Karakteristik partisipan pada penelitian ini adalah karyawan di bawah 55 tahun. Partisipan penelitian berdomisili di Jakarta, Pekanbaru, Jambi, Lampung, Palembang, Padang, Jambi, Tangerang, dan Semarang. Pada penelitian ini, sampel yang digunakan berjumlah 255 partisipan. Teknik sampling yang digunakan dalam penelitian ini adalah probability sampling dengan jenis pengambilan sampel menggunakan teknik convenience sampling.

\section{Alat ukur perilaku kerja kontraproduktif}

Alat ukur yang digunakan untuk mengukur variabel PKK adalah the interpersonal and organizational deviance scales yang terdiri dari 28 butir (Bennet \& Robinson, 2000). Alat ukur ini telah diadaptasi ke dalam bahasa Indonesia dan terdiri dari 48 butir (Suyasa, 2018). Skala yang digunakan adalah rating scale yang memiliki rentang dari 0 - 5 yang menunjukan jumlah dilakukannya perilaku yang tertera dalam butir alat ukur mulai dari tidak pernah dalam sebulan (0), satu kali dalam sebulan (1), dua kali dalam sebulan (2), tiga kali dalam sebulan (3), empat kali dalam sebulan (4), dan lima kali atau lebih dalam sebulan (5). Contoh butir pada alat ukur ini adalah "Menjaga jarak terhadap orang lain yang berasal dari suku/asal daerah tertentu", "Membicarakan orang lain sebagai bahan guyon/bercanda", dan "Mengatakan kepada orang lain mengenai berbagai keburukan yang ada di tempat kerja". Skor koefisien internal consistency reliability dimensi ini adalah 0.899 .

\section{Alat ukur machiavellianism}

Alat ukur yang digunakan untuk mengukur variabel machiavellianism adalah Mach IV yang dikembangkan oleh Christie (1970) yang terdiri dari 20 butir. Pernyataan butir dari alat ukur Mach IV ini tediri dari butir positif dan butir negatif, dengan respon menggunakan skala Likert, dimulai dari tidak setuju (TS), cenderung tidak setuju (CTS), cenderung setuju (CS), dan setuju (S). Contoh butir pernyataan positif adalah "Jangan pernah memberi tahu seseorang alasan sebenarnya kenapa Anda melakukan suatu hal kecuali jika menguntungkan Anda". Contoh butir pernyataan negatif adalah "Kejujuran adalah jalan terbaik untuk setiap persoalan". Skor koefisien internal consistency reliability alat ukur ini adalah 0.767 .

\section{Alat ukur abusive supervision}

Alat ukur yang digunakan untuk mengukur variabel abusive supervision adalah Abusive Supervision Scale yang didesain oleh Tapper (2000) yang terdiri dari 15 butir pernyataan. Skala yang digunakan adalah rating scale yang memiliki rentang dari 0 - 4 yang menunjukan jumlah dilakukannya perilaku yang tertera dalam butir alat ukur mulai dari tidak pernah(0), sesekali / jarang (1), kadang-kadang (2), sering (3), dan sering sekali (4). Contoh butir pernyataannya adalah "Atasan saya mendiamkan saya" dan "Atasan saya tidak menghargai tugas-tugas sulit yang telah saya selesaikan". Skor koefisien internal consistency reliability dimensi ini adalah 0.918 . 


\section{HASIL DAN PEMBAHASAN}

\section{Gambaran Partisipan}

Penelitian ini dilakukan pada 337 karyawan. Gambaran partisipan dapat dilihat dari usia, jenis kelamin, tingkat pendidikan, departemen, dan level jabatan pada tabel berikut.

Tabel 1.Gambaran Demografi Partisipan

\begin{tabular}{|c|c|c|c|}
\hline \multirow[t]{2}{*}{ Variabel Demografi } & \multirow[t]{2}{*}{ Demografi Kategori } & \multicolumn{2}{|c|}{ Partisipan $(\mathrm{N}=337)$} \\
\hline & & Frekuensi & Persentase \\
\hline \multirow[t]{8}{*}{ Usia } & $\leq 20$ tahun & 16 & 4.7 \\
\hline & $21-25$ tahun & 100 & 29.7 \\
\hline & $26-30$ tahun & 95 & 28.2 \\
\hline & $31-35$ tahun & 47 & 13.9 \\
\hline & $36-40$ tahun & 43 & 12.8 \\
\hline & $41-45$ tahun & 22 & 6.5 \\
\hline & $46-50$ tahun & 14 & 4.2 \\
\hline & Total & 337 & 100.0 \\
\hline \multirow[t]{3}{*}{ Jenis Kelamin } & Laki-laki & 233 & 69.1 \\
\hline & Perempuan & 104 & 30.9 \\
\hline & Total & 337 & 100.0 \\
\hline \multirow[t]{6}{*}{ Tingkat Pendidikan } & SMP & 40 & 11.9 \\
\hline & SMA & 231 & 68.5 \\
\hline & Diploma & 29 & 8.6 \\
\hline & $\mathrm{S} 1$ & 36 & 10.7 \\
\hline & $\mathrm{S} 2$ & 1 & 0.3 \\
\hline & Total & 337 & 100.0 \\
\hline \multirow[t]{7}{*}{ Departemen } & Operasional & 227 & 67.4 \\
\hline & Marketing \& Sales & 36 & 4.5 \\
\hline & HRD, GA \& Legal & 15 & 1.5 \\
\hline & Procurement & 5 & 13.1 \\
\hline & Finance \& Accounting & 44 & 1.2 \\
\hline & ITE & 6 & 1.8 \\
\hline & Total & 337 & 100.0 \\
\hline \multirow[t]{6}{*}{ Level Jabatan } & Operator / Staff & 286 & 84.9 \\
\hline & Koordinator / Foreman & 30 & 8.9 \\
\hline & SPV (Section Head) & 14 & 4.2 \\
\hline & Manager (Departemen Head) & 3 & 0.9 \\
\hline & $\begin{array}{l}\text { Chief / General Manager (Division } \\
\text { Head) }\end{array}$ & 4 & 1.2 \\
\hline & Total & 337 & 100.0 \\
\hline
\end{tabular}

Sumber : Hasil penelitian

Dari tabel 1 diketahui bahwa $69.1 \%$ partisipan adalah karyawan dengan jenis kelamin laki-laki yang paling banyak berada di rentang usia $21-25$ tahun. Mayoritas partisipan berasal dari departemen operasional yaitu $67.4 \%$ dengan persentase tingkat pendidikan SMA $68.5 \%$ dan level jabatan operator / staff adalah $84.9 \%$.

\section{Gambaran variabel perilaku kerja kontraproduktif}

Pengukuran variabel PKK memiliki skala penilaian $0-5$ dengan nilai tengah alat ukur sebesar 2.5. Hasil gambaran variabel PKK diperoleh dengan melakukan pengolahan data menggunakan analisis descriptive statistics. Nilai rata-rata variabel PKK adalah $M=0.48$ dan $S D=0.56$, 
dengan nilai minimum 0.02 dan nilai maksimum 3.14. Nilai rata-rata tersebut berada di bawah nilai titik tengah alat ukur. Berdasarkan analisis deskritif di atas diketahui bahwa mean PKK di PT X cenderung rendah.

\section{Gambaran variabel machiavellianism}

Pengukuran variabel machiavellianism memiliki skala penilaian $1-4$ dengan nilai tengah alat ukur sebesar 2.5. Hasil gambaran sifat machiavellianism diperoleh dengan melakukan pengolahan data menggunakan analisis descriptive statistic. Nilai rata-rata machiavellianism adalah $M=1.89$ dan $S D=0.35$, dengan nilai minimum 1.00 dan nilai maksimum 2.67. Nilai ratarata tersebut berada di bawah nilai titik tengah alat ukur. Berdasarkan analisis deskriptif di atas diketahui bahwa mean machiavellianism karyawan di PT X cenderung rendah.

\section{Gambaran variabel abusive supervision}

Pengukuran variabel abusive supervision memiliki skala penilaian $0-4$ dengan nilai tengah alat ukur sebesar 2. Hasil gambaran abusive supervision diperoleh dengan melakukan pengolahan data menggunakan analisis descriptive statistic. Nilai rata-rata abusive supervision adalah $M=0.40$ dan $S D=0.57$, dengan nilai minimum 1.00 dan nilai maksimum 2.72 . Nilai rata-rata tersebut berada di bawah nilai titik tengah alat ukur. Berdasarkan analisis deskriptif di atas diketahui bahwa mean abusive supervision yang dipersepsikan karyawan di PT X cenderung rendah.

\section{Pengujian hipotesis}

Berdasarkan empat syarat yang dinyatakan oleh Baron dan Kenny (1986), peneliti menguji syarat pertama di mana hubungan antara sifat machiavellianism (X) dengan PKK (Y) menunjukkan adanya hubungan yang signifikan antara keduanya $(\mathrm{t}=8.253>1.962)$. Syarat kedua diuji di mana hubungan antara machiavellianism (X) dengan abusive supervision (M) menunjukkan adanya hubungan yang signifikan antara keduanya $(\mathrm{t}=3.589>1.962)$. Syarat ketiga diuji di mana Abusive Supervision (M) dengan PKK (Y) menunjukkan adanya hubungan yang signifikan antara keduanya $(\mathrm{t}=2.347>1.962)$. Syarat keempat diuji di mana hubungan antara sifat machiavellianism (X) dengan PKK (Y) saat abusive supevision (M) diperhitungkan sebagai mediator menunjukkan hasil yang tidak signifikan $(\mathrm{t}=1.579<1.962)$. Hal tersebut menunjukkan bahwa abusive supervision berfungsi sebagai mediator secara penuh pada hubungan machiavellianism dengan PKK.

Tabel 2. Pengujian Hipotesis

\begin{tabular}{lccc}
\hline & $r$ & T Statistics & P Values \\
X ke Y & 0.508 & 8.253 & 0.000 \\
X ke M & 0.229 & 3.589 & 0.000 \\
M ke Y & 0.174 & 2.347 & 0.019 \\
X ke M ke Y & 0.040 & 1.579 & 0.115 \\
\hline
\end{tabular}

Berdasarkan hasil yang diperoleh, ditemukan bahwa abusive supervision berperan sebagai mediator pada hubungan karyawan machiavellianism dengan PKK. Hasil penelitian menunjukkan bahwa tingkat machiavellianism di PT X cenderung rendah. Hal ini berarti semakin rendah machiavellianism karyawan, maka persepsi buruk terhadap atasan juga rendah sehingga PKK yang terjadi di PT X pun juga cenderung rendah. 
Peneliti menduga rendahnya PKK yang terlihat pada penelitian ini bukan hanya disebabkan oleh rendahnya machiavellianism karyawan dan abusive supervision yang rendah. Terdapat faktorfaktor lain yang memengaruhi rendahnya PKK di PT X. Pertama, butir-butir yang ada dalam alat ukur PKK mengandung perilaku-perilaku negatif yang bertentangan dengan norma sosial sehingga individu cenderung menampilkan hal-hal baik dan menutupi hal buruk yang ada pada dirinya. Kedua, adanya bias dalam pengambilan data. Peneliti merupakan karyawan internal PT $\mathrm{X}$ sehingga karyawan PT X tidak ingin perilaku kerja kontraproduktifnya terdeteksi. Hal ini sejalan dengan penelitian dari Pecker dan Fine (2015) di mana tingkat PKK cenderung sangat rendah. Menurutnya hal ini disebabkan oleh adanya penilaian subyektif partisipan (Pecker \& Fine, 2015) dan karyawan tidak ingin terdeteksi melakukan PKK (Sackett \& DeVore, 2005).

Fenomena di lapangan menunjukkan bahwa karyawan melakukan PKK di antaranya datang terlambat, istirahat lebih dari waktu yang ditentukan, menggunakan waktu kerja untuk berdagang dan mendiskusikan hal yang tidak berkaitan dengan pekerjaan. Hal ini dapat menyebabkan karyawan membutuhkan waktu kerja tambahan untuk menyelesaikan tugasnya yang di kompensasikan dengan lembur. Sejalan dengan penelitian ini, ditemukan bahwa PKK yang paling banyak dilakukan oleh karyawan adalah mengusahakan pekerjaan yang bersifat lembur. Hal tersebut tentunya dapat meningkatkan biaya lembur dan operasional perusahaan serta mengurangi laba perusahaan.

Seperti yang dijelaskan di atas, rendahnya PKK dapat dijelaskan oleh rendahnya machiavellianism karyawan pada penelitian ini. Peneliti menduga rendahnya machiavellianism karyawan sendiri dikarenakan Mach IV Scale berlaku untuk umum dan tidak berhubungan dengan konteks tertentu seperti tempat kerja. Ada kemungkinan bahwa individu mungkin berperilaku berbeda di setiap situasi (Pervin \& John, dalam Kessler et al., 2010), terutama dalam konteks yang berbeda seperti pekerjaan dan kehidupan pribadinya.

Hasil penelitian menunjukkan bahwa machiavellianism memiliki hubungan positif dan signifikan dengan abusive supervision $(r=0.029, p<0.01)$. Hal ini sejalan dengan penelitian-penelitian sebelumnya dari Kiazad dan kolega (2010) $(r=0.34, p<0.01)$ serta penelitian Wisee dan Skebos (2016) $(r=0.30, p<0.01)$. Salah satu ciri khas dari machiavellianism adalah pandangan sinis terhadap orang lain (Jones \& Paulhus, 2009). Ia tidak mempercayai orang lain karena ia memiliki kecenderungan untuk berperilaku manipulatif, sehingga ia berpikiran bahwa orang lain juga dapat berperilaku demikian kepadanya (Greennaum et al., 2014).

Pada dunia kerja, karyawan dengan machiavellianism yang tinggi cenderung memiliki tingkat perasaan negatif yang tinggi (Dahling et al, 2009) dan lebih cenderung tidak mempercayai orang lain termasuk atasan atau pemimpinnya (Dirks \& Ferrin, 2002). Sensitivitas dan perasaan negatif tersebut mempengaruhi persepsinya terhadap perilaku atasan. Semakin tinggi machiavellianism seseorang, semakin tinggi pula seseorang menilai atasannya buruk. Begitu pula sebaliknya, semakin rendah machiavellianism seseorang, maka semakin rendah pula ia menilai atasannya buruk.

Namun, jika melihat besaran hubungan machiavellianism dengan abusive supervision, peneliti menduga lebih lemahnya hubungan machiavellianism pada abusive supervision pada penelitian ini dibandingkan penelitian sebelumnya dikarenakan oleh adanya perbedaan subyek penelitian. Penelitian sebelumnya (Kiazad et al., 2010 ; Wisee \& Skebos, 2016) melihat bagaimana atasan dengan sifat machiavellianism berhubungan dengan persepsi bawahan terhadap atasan. Sedangkan pada penelitian ini, peneliti melihat bagaimana karyawan dengan sifat 
machiavellianism berhubungan dengan persepsinya terhadap atasan. Hal ini tentunya memberikan pengaruh dan hubungan yang berbeda terhadap persepsi bawahan terhadap atasan.

Abusive supervision memiliki peranan sebagai mediator secara menyeluruh pada hubungan machiavellianism dengan PKK. Dengan kata lain, hubungan machiavellianism dengan PKK diperkuat oleh mekanisme abusive supervision. Hubungan abusive supervision dengan PKK dapat dijelaskan dengan teori pertukaran sosial (social exchange theory). Hukum timbal balik merupakan hal yang paling penting dalam pertukaran sosial. Saat karyawan menerima perlakuan baik, hormat, dan diterima maka mereka akan membayarnya dengan berkomitmen tinggi pada organisasi. Namun sebaliknya, jika karyawan menerima perilaku tidak baik dan kasar dari atasan, maka mereka akan membalasnya (Zellar, Tepper, \& Duffy, 2003). Tepper (2007) menjelaskan bahwa ketika bawahan tidak dapat menghentikan atau membalas atasannya, maka mereka cenderung mengambil tindakan yang merugikan bahkan membahayakan organisasi.

Uzondu dan kolega (2017) menjelaskan bahwa atasan memegang peranan penting dalam membentuk komitmen karyawan perilaku kerja kontraproduktif. Korban dari perlakuan abusif atasan percaya bahwa organisasi bertanggung jawab dengan mengizinkan atasannya berprilaku demikian kepadanya. Mereka percaya bahwa organisasi tidak peduli terhadap kesejahteraan karyawan, sehingga saat bawahan tidak dapat menghentikan atau membalas langsung atasannya, mereka cenderung menarik diri dan melakukan pembalasan ke organisasi dengan melakukan tindakan kontraproduktif.

Saat karyawan dengan machiavellianism yang tinggi memiliki abusive supervision yang tinggi akan mengakibatkan perilaku kerja kontraproduktif yang tinggi pula. Hal ini harus diantisipasi dengan dimoderasi oleh variabel lain yang dapat memengaruhi hubungan machiavellianism dengan absuive supervision seperti variabel iklim organisasi.

\section{KESIMPULAN DAN SARAN}

\section{Kesimpulan}

Berdasarkan analisis data yang telah dilakukan, diketahui bahwa abusive supervision berperan sebagai mediator secara penuh pada hubungan machiavellianism dengan PKK. Hal ini berarti variabel machiavellianism dapat memprediksi PKK dengan dijelaskan melalui mekanisme abusive supervision.

\section{Saran}

Peneliti menyarankan pada penelitian berikutnya untuk melakukan penelitian eksperimental guna menghindari bias dan rasa tidak aman atau khawatir bagi partisipan yang dapat memberikan efek tidak langsung pada hasil penelitian. Selain itu, pada penelitian selanjutnya diharapkan dapat melakukan pengukuran machiavellianism secara spesifik dengan menggunakan alat ukur organizational machiavellianism sehingga dapat diperoleh gambaran penelitian yang lebih spesifik.

Peneliti menyarankan bagi perusahaan untuk dapat menambahkan tes machiavellianism pada saat proses rekrutmen. Selain itu, diharapkan perusahaan dapat memberikan pelatihan kepada pemimpin untuk mampu melayani dan mengayomi bawahannya dengan baik (servant leader). Diharapkan pula para pemimpin dapat memberikan umpan balik dan apresiasi kepada bawahan sehingga karyawan merasa dihargai dan diterima. Hal ini berguna untuk mencegah atau 
meminimalisir munculnya perilaku kerja yang kontraproduktif maupun tidak etis. Bagi karyawan, disarankan untuk dapat menyalurkan emosi negatif dalam bentuk yang positif seperti konseling kepada bagian pengembangan karyawan di perusahaan.

\section{Ucapan Terima Kasih (Acknowledgement)}

Peneliti mengucapkan terima kasih kepada pihak perusahaan yang telah memberikan kesempatan kepada peneliti untuk melakukan penelitian di perusahaan. Terima kasih kepada partisipan yang telah meluangkan waktu untuk mengikuti penelitian ini.

\section{REFERENSI}

An, F., \& Wang, B. (2016). Abusive supervision and counterproductive work behavior: Moderating effect of negative affectivity. Journal of Service Science and Management, 9, 6673.

Amir, T. S., \& Malik. A. A. (2016). Machiavellianism and counterproductive work behavior at workplace. Journal of Educational \& Social Sciences, (4)1, 14-29. Doi $10.20547 /$ jess 0411604102

Anderson, N. (2005). Handbook of Industrial, Work, and Organizational Psychology. Volume 1. pp.123-162. London: Sage.

Baloch, M. A., Meng, F., Xu, Z., Cepeda-Carrion, I., Danish., \& Bari. M. W. (2017). Dark triad, perceptions of organizational politics and counterproductive work behaviors: The moderating effect of political skills. Frontier in Psychology, 8(1972), 1-14.

Baron, R. M., \& Kenny, D. A. (1986). The moderator-mediator variable distinction in social psychological research: Conceptual, strategic, and statistical considerations. Journal of Personality and Social Psychology, 51(6), 1173-1182. doi: 10.1037/0022-3514.51.6.1173

Bennett, R. J., \& Robinson, S. L. (2000). Development of a Measure of Workplace Deviance. Journal of Applied Psychology, 85(3), 349-360.

Bolton, L. R., Becker, L. K., \& Barber, L. K. (2010). Big Five trait predictors of differential counterproductive work behavior dimensions. Personality and Individual Differences, 49, 537-541. doi: 10.1016/j.paid.2010.03.047

Christie, R. (1970). Scale construction. In R. Christie \& F. Geis (Eds.), Studies in Machiavellianism (pp. 10-34). New York: Academic Press.

Cohen, A. (2016). Are they among us? A conceptual framework of the relationship between the dark triad personality and counterproductive work behaviors (CWBs). Human Resouces Management, 26, 69-85. doi: 10.1016/j.hrmr.2015.07.003.

Darmawan, D. (2013). Prinsip-prinsip Perilaku Organisasi. Surabaya: Pena Semesta.

Dirks, K. T., \& Ferrin, D. L. (2002). Trust in leadership: Meta-analytic findings and implications for research and practice. Journal of Applied Psychology, 87(4), 611-628. doi: 10.1037/00219010.87.4.611

Greennaum, R. L., Mawritz, M. B., \& Quade, M. J. (2014). Employee machiavellianism to unethical behavior: The role of abusive supervision as a trait activator. Journal of Management, 43(2), 585-609. doi: 10.1177/0149206314535434

Hafidz, S. W. M. (2012). Individual differences as antecedents of counterproductive work behaviour. Asian Social Science, 7, (13), 220-226.

Harris, K. J., Kacmar, K. M., \& Zivnuska, S. (2007). An investigation of abusive supervision as a predictor of performance and the meaning of work as a moderator of the relationship. The Leadership Quarterly, 18(3), 252-263. doi: 10.1016/j.leaqua.2007.03.007 
Harvey, P., Stoner, J., Hochwarter, W., \& Kacmar, C. (2007). Coping with abusive supervision: The neutralizing effects of ingratiation and positive affect on negative employee outcomes. The Leadership Quarterly, 18(3), 264-280. doi: 10.1016/j.leaqua.2007.03.008

Jensen, J. M., \& Patel, P. C. (2011). Predicting counterproductive work behavior form interaction of personality traits. Personality and Individual Differences, 51, 466-471. doi: 10.1016/j.paid.2011.04.016

Jones, D. N., \& Paulhus, D. L. (2009). Machiavellianism. In, M. R. Leary \& R. H. Hoyle (Eds.), Handbook of individual differences in social behavior (pp. 257-273). New York, NY: The Guilford Press.

Kessler, S. (2010). Re-examining machiavelli: A three-dimensional model of machiavellianism in the workplace. Journal of Applied Social Psychology, 40(8), 1868-1896.

Kiazad, K., Restubog. S. L. D., Zagenczyk, T. J., Kiewitz, C., Tang, R. L. (2010). In pursuit of power: The role of authoritarian leadership in the relationship between supervisors' Machiavellianism and subordinates' perceptions of abusive supervisory behavior. Journal of Research in Personality, 44, 512-519.

Kish-Gephart, J. J., Harrison, D. A, \& Treviño, L. K. (2010). Bad apples, bad cases, and bad barrels: meta-analytic evidence about sources of unethical decisions at work. Journal Applied Psychology, 95, 1-31. doi: 10.1037/a0017103

Mackey, J., Frieder, R. E., Bress, J., Martinko, M. J. (2016). Abusive Supervision: A metaAnalysis and Empirical Review. Journal of Management, 43(6), 1940-1965. doi: $10.1177 / 0149206315573997$

Michael, M., Ilies, R., \& Johnson, E. (2006). Relationship of personality traits and counterproductive work behaviors: The mediating effects of job satisfaction. Personnel Psychology, 59, 591-622.

Mitchell, M. S., \& Ambrose, M. L. (2007). Abusive supervision and workplace deviance and the moderating effects of negative reciprocity beliefs. Journal of Applied Psychology, 92(4), 1159-1168.

Nurul, I., Kozako, A. M. F., Safin, S. Z., \& Rahim, A. R. A. (2013). The relationship of big five personality traits on counterproductive work behaviour among hotel employee: An Exploratory study. Procedia, 7, 181-187.

O'Boyle, E. H., Forsyth, D. R., and O'Boyle, A. S. (2011). Bad apples or bad barrels: an examination of group and organizational level effects in the study of counterproductive work behavior. Group \& Organization Management, 36 (1), 39-69. doi: $10.1177 / 1059601110390998$

O’Boyle, E. H., Forsyth, D. R., Bank, G. C., \& McDaniel, M. A. (2012). A Meta-analysis of the dark triad and work behavior: a social exchange perspective. Journal of Applied Psychology, 97, 557-579. Doi: 10.1037/a0025679.

Pecker, G., \& Fine, S. (2015, May). Using exit surveys to evaluate counterproductive work behaviors. Paper to be presented at the 17th Conference of the European Association of Work and Organizational Psychology, Oslo, Norway.

Piskin, M., Kart, M. E., Savci, I., \& Guldu, O. (2014). Counterproductive work behavior in relation to personality type and cognitive distortion level in academics. International Association of Social Science Research, 2 (6), 212-217. ISSN: 2147-6284.

Raman, P., Sambasivan, M., \& Kumar, N. (2016). Counterproductive work behavior among frontline government employees: Role of personality, emotional intelligence, affectivity, emotional labor, and emotional exhaustion. Journal of Work and Organizational Psychology, 32, 25-37.

Robinson, S. L., \& Bennett, R. J. (1995). A Typology of deviant workplace deviance: A multidimensional scaling study. Academy of Management Journal, 38(2), 555-572. 
Robinson, S. L., \& Bennett, R. J. (1997). Workplace deviance: Its definition, its manifestations, and its causes. In R. J. Lewicki, R. J. Bies, \& B. H. Sheppard (Eds.), Research on negotiation in organizations, Vol. 6, pp. 3-27. US: Elsevier Science/JAI Press.

Sackett, P. R., \& DeVore, C. J. (2005). Counterproductive behaviors at work. In. N. Anderson, D. S. Ones, H. K. Sinangil, C. Viswesvaran (eds.). Handbook of Industrial, Work andOrganizational Psychology (pp. 145-164). London: Sage Publications.

Schat, A. C. H., Demarais, S., \& Kelloway, E. K. (2006). Exposure to workplace aggression from multiple sources: A validation of a measure and test of a model. Unpublished manuscript, McMaster University, Hamilton, Canada.

Scott, B. A., \& Judge, T. A. (2013). Beauty, personality, and affect as antecedents of counterproductive work behavior receipt. Human Performance, 26, 93-113. doi: 10.1080/08959285.2013.765876

Sedarmayanti. (2009). Sumber Daya Manusia dan Produktivitas Kerja. Bandung: Mandar Maju.

Spector, P.E., Fox, S., Penney, L. M., Bruursema, K., Goh, A., \& Kessler, S. (2006). The dimensionality of counterproductivity: Are all counterproductive behavior created equal? Journal of Vocational Behavior, 68(3), 446-460.

Stanescu, D. F., \& Mohorea , L. (2016). Welcome to the dark side: A correlational study od the dark triad of personality with counterproductive work behavior and work of locus. Pannon Management Review, 5(1-2), 47-57.

Sulea, C., Fine, S., Fischmann, G., Sava, F. A., Dumitru, C. (2013). Abusive supervision and counterproductive work behaviors: The moderating effect of personality. Journal of Personnel Psychology, 12(4), 196-200. Doi: 10.1027/1866-5888/a000097

Suyasa, P. T. Y. S. (2017). The role of quality of the work life as predictor of counterproductive work behavior. Anima Indonesia Psychological Journal, 32(3), 169-183.

Thakur, K. (2017). Personality in relation to counterproductive work behaviour: A study on the employees of manufacturing industry. International Journal of Management and Applied Science, 3 (4), 49-52.

Tepper, B. J. (2000). Consequences of abusive supervision. Academy of Management Journal, 43(2), 178-190.

Tepper, B. J., Duffy, M. K., \& Shaw., J. D. (2001). Personality moderators of the relationship between abusive supervision and subordinates' resistance. Journal of Applied Psychology, 86(5), 974-983.

Tepper B. J., Duffy M. K., Hoobler J., Ensley M. D. (2004). Moderators of the relationship between coworkers' organizational citizenship behavior and fellow employees' attitudes. Journal Applied Psychology, 89, 455-465. doi: 10.1037/0021-9010.89.3.455

Tepper B. J. (2007). Abusive supervision in work organizations: review, synthesis, and directions for future research. Journal Management, 33, 261-289. doi: $10.1177 / 0149206307300812$

Uzondu, C. N., Nwonyi, S. K., \& Ugwumgbor, E. T. (2017). Abusive supervision, work tension and overload as predictors of counterproductive work behavior. International Journal of Health and Psychology Research, 5(3), 37-48.

Wisse, B. \& Sleebos, E. (2016). When the dark ones gain power : Perceived position power strengthens the effect of supervisor machiavellianism on abusive supervision in work team. Personality and Individual Differences, 99, 122-126.

Zellars, K. L., Tepper, B. J., \& Duffy, M. K. (2002). Abusive supervision and subordinates' organizational citizenship behavior. Journal of Applied Psychology, 87(6), 1068-1076. doi: 10.1037/0021-9010.87.6.1068 